This item was submitted to Loughborough's Research Repository by the author.

Items in Figshare are protected by copyright, with all rights reserved, unless otherwise indicated.

\title{
Switching a dual band PIFA to operate in four bands
}

PLEASE CITE THE PUBLISHED VERSION

PUBLISHER

(C) Institute of Electrical and Electronics Engineers (IEEE)

LICENCE

CC BY-NC-ND 4.0

REPOSITORY RECORD

Wu, J., C.J. Panagamuwa, Patrick McEvoy, J.C. Vardaxoglou, and Omar A. Saraereh. 2019. "Switching a Dual Band PIFA to Operate in Four Bands". figshare. https://hdl.handle.net/2134/2954. 
This item was submitted to Loughborough's Institutional Repository by the author and is made available under the following Creative Commons Licence conditions.

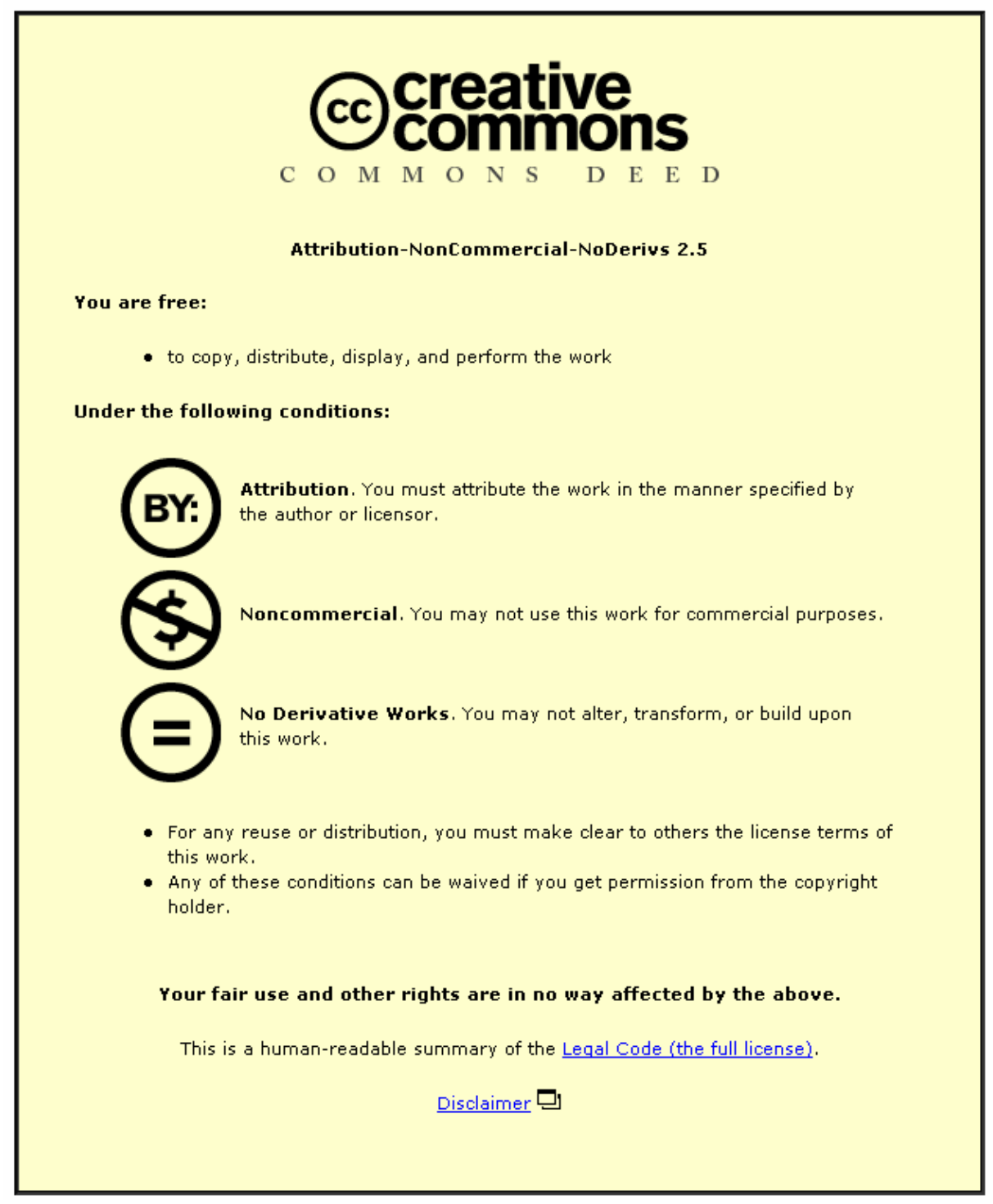

For the full text of this licence, please go to: http://creativecommons.org/licenses/by-nc-nd/2.5/ 


\title{
Switching A Dual Band PIFA To Operate In Four Bands
}

\author{
Junfeng $\mathrm{Wu}^{(1)}$, Chinthana J. Panagamuwa ${ }^{(1)}$, Patrick McEvoy ${ }^{(1) *}$, \\ John (Yiannis) C. Vardaxoglou ${ }^{(1)}$ and Omar A. Saraereh ${ }^{(2)}$ \\ (1) Centre for Mobile Communications Research, Loughborough University, \\ Loughborough, LEICS., LE11 3TU, United Kingdom. \\ Web: http://cmcr.lboro.ac.uk Email: P.McEvoy@,lboro.ac.uk \\ (2) Electrical and Computer Engineering Dept, Hashemite University, Al-Zarqa, \\ Jordan
}

\section{Introduction}

Competitive global marketing in the mobile phone sector has driven demand for small phone terminals capable of multi-band operation across standard mobile communication bands. There is restriction on the antenna size due to the presence of various integrated components for different applications in contemporary handsets. The antenna should also be reasonably efficient and free of excessive radiation illuminating the user's head (low SAR value). PIFAs are widely used as an internal antenna solution. They have desirable features such as high efficiency multi-frequency behavior, moderate bandwidth, low profile, low cost, less prone to breakage and reduced user power absorption compared with equivalent external antennas. For US or European GSM systems, the antenna should be matched to either the GSM850 / GSM1900 bands or the GSM900 / GSM1800 bands.

The antenna presented here is based on a small [1] dual band PIFA with maximum dimensions $36 \mathrm{~mm} \times 12 \mathrm{~mm} \times 6 \mathrm{~mm}$. This size is typical of a PIFA designed for a contemporary mobile phone. While versitile, at lower frequencies it is often difficult to completely cover the GSM850 and EGSM 900 bands simultanously using a small antenna. In this paper, a PIFA is reported with switches to select between two sets of low and high resonance pairs. The antenna has been designed with the intention to operate in either of the GSM850/GSM1900 and GSM900/GSM1800 band pairs, while being manufactured with standard planar phototihography processes.

\section{Modelling}

Initial modelling was carried out using IMST's Empire [2], FDTD simulation tool. The PIFA was studied in its basic structure, i.e. without switched components. This showed that empirical prototypes could adopt the structure with simple concept switches to tune the antenna to the required resonant frequency pair. Figure 1 illustrates the antenna structure on a phone ground plane $(40 \mathrm{~mm} \times 100 \mathrm{~mm})$ with the feed and shorting points.

\section{Empirical Experiments}

Figure 2 illustrates the design of the empirical PIFA in the X-Y plane. It shows two switches (S1 and S2), which when shorted, act to lengthen the two resonant modes present on the antenna. In this paper, Mode 1 corresponds with a resonant pair covering most of the GSM850 and GSM1900 bands, in addition to fully covering the UMTS band. Mode 2 covers the GSM900 and GSM1800 bands. Switch 1 spans a $1.0 \mathrm{~mm}$ gap and switch 2 spans a $0.9 \mathrm{~mm}$ gap. Initially, the switches were implemented using copper tape.

\section{Results}

Figure 4 shows results for the matched resonance of the PIFA in the two modes. Mode 1 (the continuous line) operates at $875.5 \mathrm{MHz}(4.78 \% \mathrm{BW})$ and $2000 \mathrm{MHz}(12.37 \% \mathrm{BW})$. 
Mode 2 (the dashed line) operates at $893.5 \mathrm{MHz}(5.04 \% \mathrm{BW})$ and $1802.5 \mathrm{MHz}(10.62 \%$ $\mathrm{BW})$. This is a $18 \mathrm{MHz}$ shift in the lower bands and a $200 \mathrm{MHz}$ shift in the upper band.

Figures 5 and 6 show the normalised patterns for the PIFA at the four resonant modes in E-Theta and E-Phi polarisations. Handling the device showed that the unbalance feed typical of this structure results in currents resonating on the ground plane. The height of the antenna above the ground plane is also critical to the bandwidth of the modes.

\section{Conclusions}

A PIFA antenna with dimensions suitable for a contemporary mobile phone handset is presented. The proof-of-concept switches show the potential for selecting between US and European GSM bands without the antenna design size being increased, which is normally required of quadband antennas. Balancing the antenna's feed will improve its handling performance by de-coupling the influence of the user's hand and raising the height of the PIFA above the ground plane will broaden the resonant bandwidth. It is believed that these modifications will enable the bandwidth requirements to be fully compliant at a $-5 \mathrm{~dB}$ match level. Small PIFA antennas support compact and hybrid resonant modes which are sensitive to manufacturing tolerances and typically low in bandwidth. By reducing the mode coupling across the structure, the modes can be switched to different frequencies for selected operation MEMS [3] and optically controlled switch devices [4] are suitable for this type of structure and are included in further work on this project.

\section{Acknowledgements}

The authors wish to thank IMST, Germany for support in modelling the antenna and Dr C.T.P. Song, Mobile Devices, Motorola (formally Sendo), Birmingham for discussions.

\section{References}

[1] "Quad-band handset antenna operation for GSM900/DCS1800/PCS1900/UMTS" Saraereh, O.A.; Jayawardene, M.; McEvoy, P.; Vardaxoglou, J.C.; Wideband and Multi-band Antennas and Arrays, 2005. IEE (Ref. No. 2005/11059) 2005 Page(s): 129 - 134

[2] IMST GmbH, "User and Reference Manual for the 3D-EM Time Domain Simulator", Part V Theoretical Background, 1998-2004.

[3] "MEMS-Based Reconfigurable Antennas", Panaia, P.; Luxey, C.; Jacquemo, G.; Stara, R.; Kossiava, G.; Dussopt, L.; Vacherand, F.; Billard, C.;Industrial Electronics, 2004 IEEE International Symposium on Volume 1, 04-07 May 2004 Page(s):175 - 179.

[4] "Frequency and Beam Reconfigurable Antenna Using Photoconducting Switches", Chinthana J. Panagamuwa, Alford Chauraya, J. (Yiannis) C. Vardaxoglou, IEEE Trans. Antennas and Propagation, Vol. 54, No 2, February 2006.

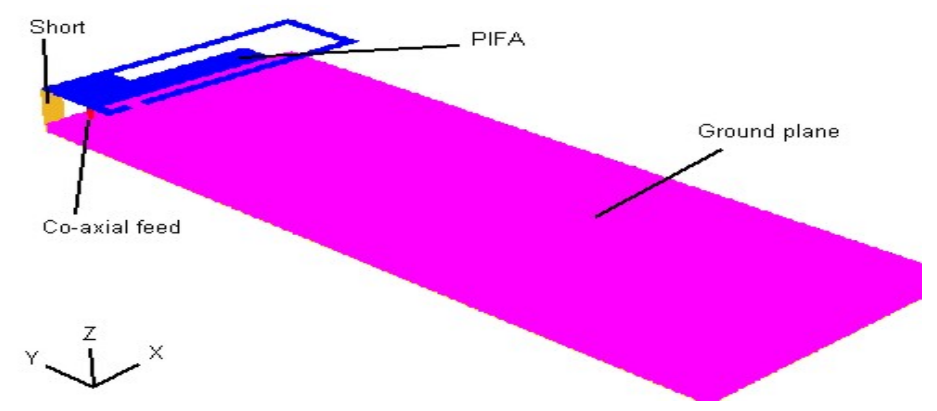

Figure 1 PIFA on a mobile phone ground plane. 


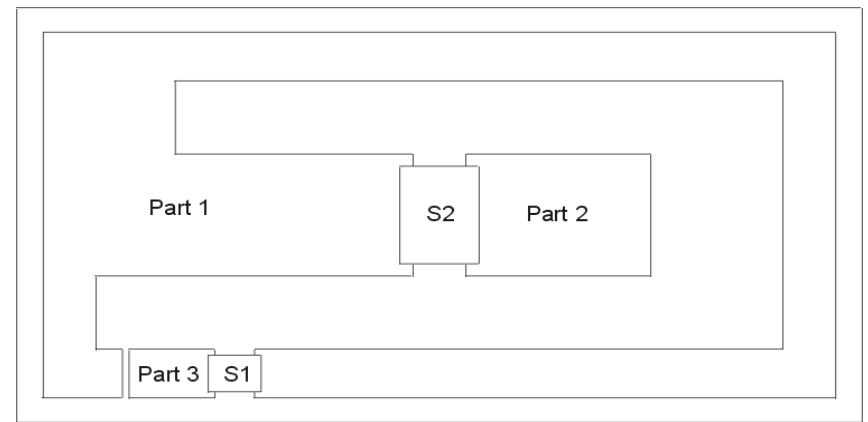

Figure 2 The X-Y plane of the switched PIFA.
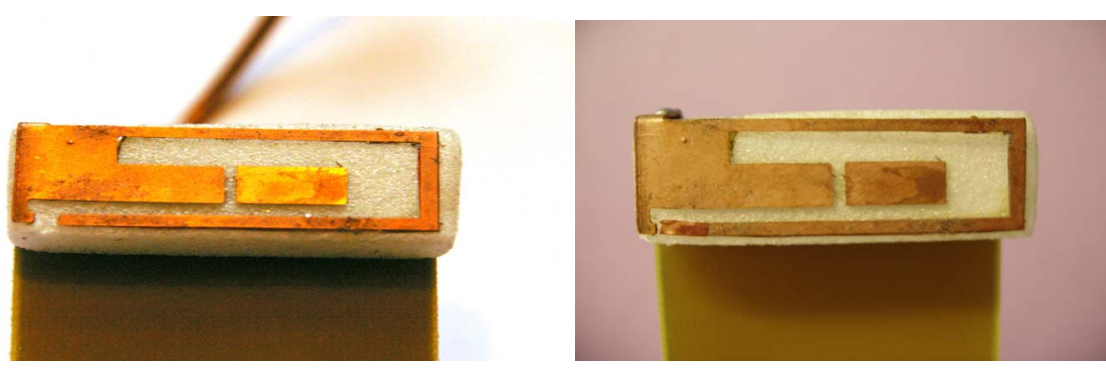

Figure 3 Photographs of the PIFA without (left) and with a Mode 1 switch (right)

\begin{tabular}{|c|c|c|}
\hline Resonant Bands & Switch/ Mode 1 & Switch/ Mode 2 \\
\hline $850 / 1900 / 2100 \mathrm{MHz}$ & ON & OFF \\
\hline $900 / 1800 \mathrm{MHz}$ & OFF & ON \\
\hline
\end{tabular}

Table 1 Switch settings modes 1 and 2

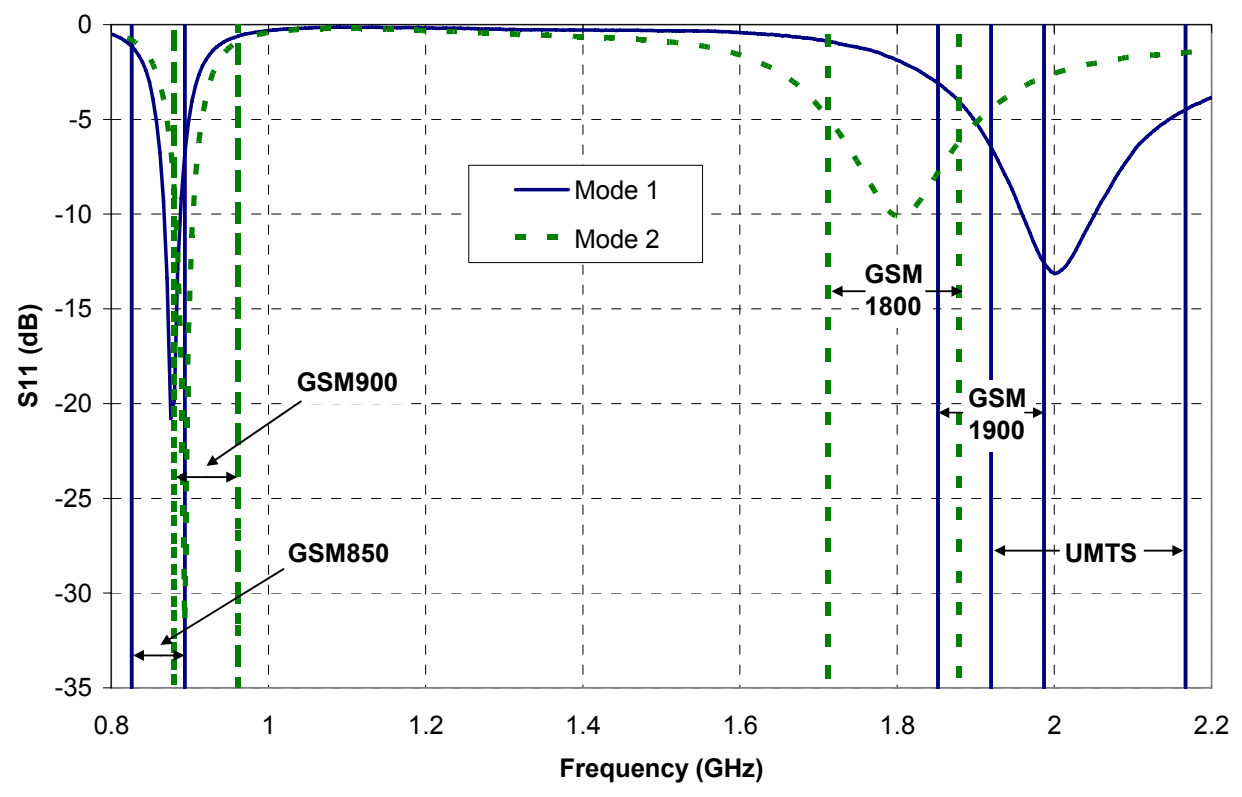

Figure 4 Matched resonance of the antenna 

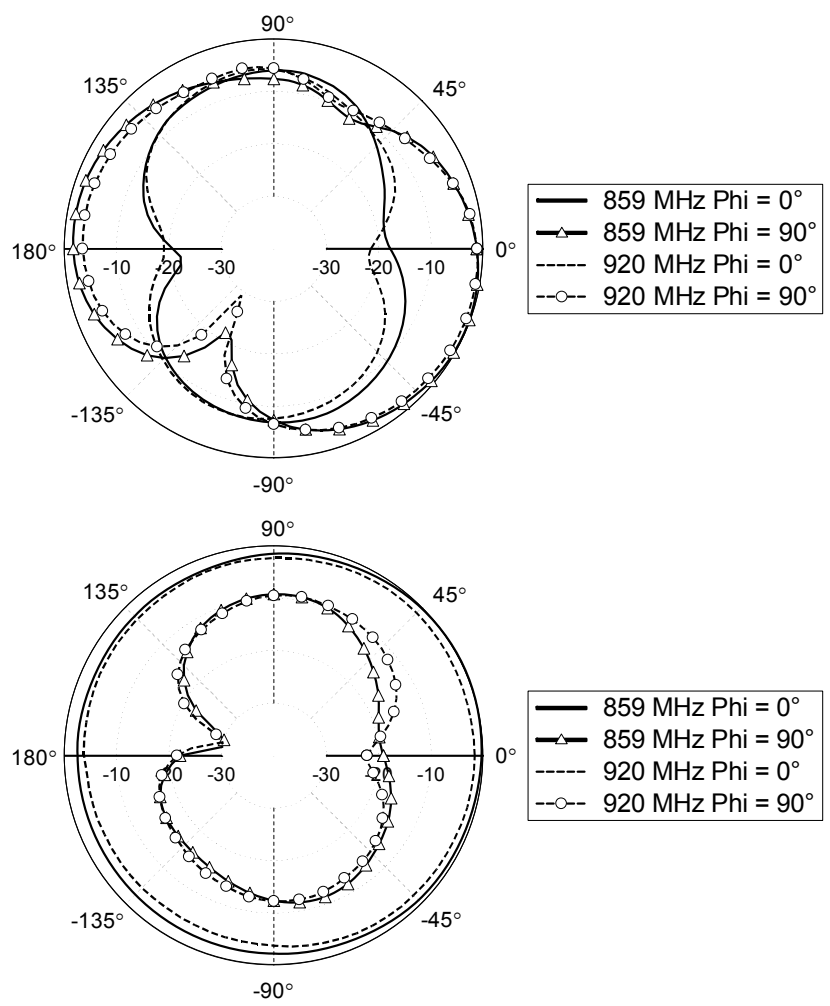

Figure 5 Lower band E-Theta (top) and E-Phi in $\mathrm{XZ}$ plane $\mathrm{Phi}=0^{\circ}, \mathrm{YZ}$ plane $\mathrm{Phi}=90^{\circ}$
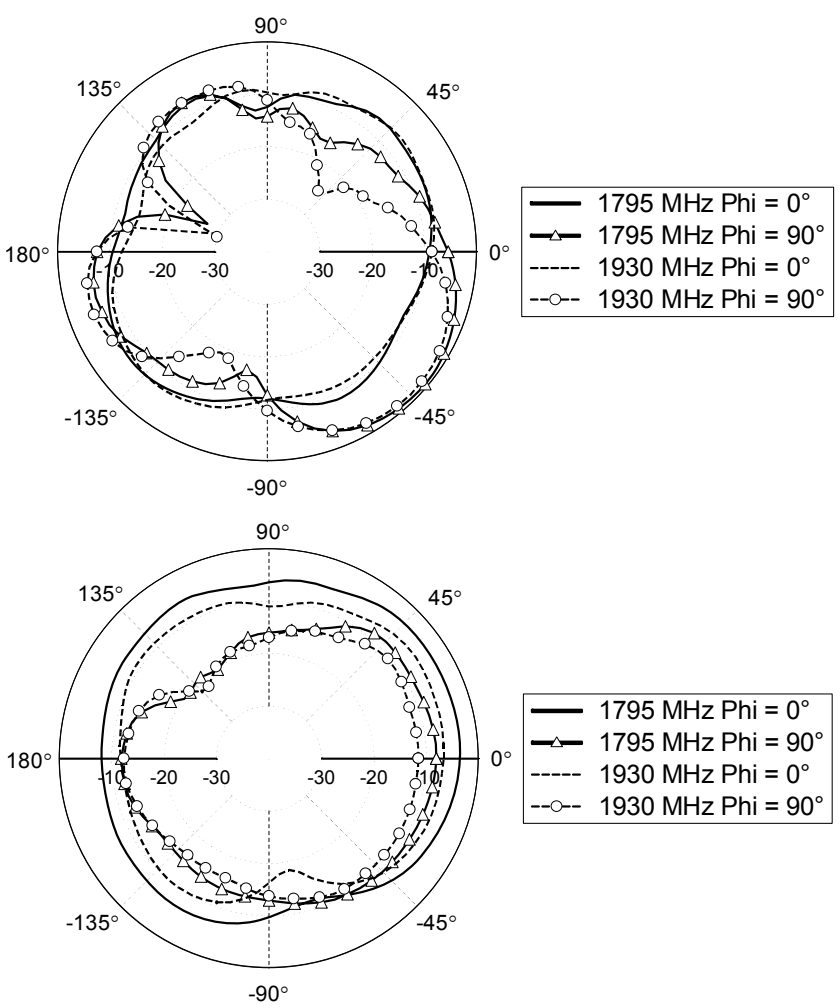

Figure 6 Upper band E-Theta (top) and E-Phi in $\mathrm{XZ}$ plane $\mathrm{Phi}=0^{\circ}, \mathrm{YZ}$ plane $\mathrm{Phi}=90^{\circ}$ 